\title{
Patterns of size sexual dimorphism in Australopithecus afarensis: Another look
}

\author{
S.-H. Lee* \\ Department of Anthropology, University of California at Riverside, Riverside, \\ CA 92521-0418, USA
}

Received 4 February 2004; accepted 20 July 2005

\begin{abstract}
Size sexual dimorphism is one of the major components of morphological variation and has been associated with socioecology and behavioral variables such as mating patterns. Although several studies have addressed the magnitude and pattern of sexual dimorphism in Australopithecus afarensis, one of the earliest hominids, consensus has yet to be reached. This paper uses assigned resampling method, a data resampling method to estimate the magnitude of sexual dimorphism without relying on individual sex assessments, to examine the fossil hominid sample from Hadar. Two questions are asked: first, whether sexual dimorphism in a selected sample of skeletal elements of $A$. afarensis is the same as that in living humans, chimpanzees, or gorillas; and second, whether different skeletal elements reflect variation in sexual dimorphism in the same way. All possible metric variables were used as data in applying the method, including seven variables from three elements (mandibular canine, humerus, femur). Analyses show that $A$. afarensis is similar in size sexual dimorphism to gorillas in femoral variables, to humans in humeral variables, and to chimpanzees in canine variables. The results of this study are compatible with the hypothesis that the pattern of sexual dimorphism in A. afarensis is different from any that are observed in living humans or apes. (C) 2005 Elsevier GmbH. All rights reserved.
\end{abstract}

\footnotetext{
*Tel.: + 19518274388 ; fax: + 19518275409 .

E-mail address: shlee@ucr.edu.
}

0018-442X/\$ - see front matter (C) 2005 Elsevier GmbH. All rights reserved. doi:10.1016/j.jchb.2005.07.001 


\section{Introduction}

Size sexual dimorphism is one of the components of morphological variation within species (Wood, 1976), and its magnitude has been associated with socioecological and behavioral variables such as mating patterns (Frayer and Wolpoff, 1985; Plavcan, 2001; Plavcan et al., 2002). Hence, exploring the sexual dimorphism in early hominids can help understand their social structure and adaptation. In that sense, it is of particular interest to examine sexual dimorphism of Australopithecus afarensis, one of the earliest hominids.

The range of morphological variation in $A$. afarensis has been a topic of debate for a long time. The fossil hominid sample encompasses a high level of variation that some researchers have argued is too high to be explained by a single species (e.g. Olson, 1985; Zihlman, 1985), although this does not represent the mainstream opinion. Rather, the range of variation in $A$. afarensis has been explained by a high level of sexual dimorphism, an interpretation put forth by the researchers of the earliest findings (Johanson and White, 1979; Johanson et al., 1978). This position has gained support from other researchers who have argued for a high level of body size sexual dimorphism based on posterior dentition and postcrania (Cole and Smith, 1987; Frayer and Wolpoff, 1985; Johanson and White, 1979; Johanson et al., 1978; Jungers, 1988b; Kimbel and White, 1988; Leutenegger and Shell, 1987; Lockwood et al., 1996; McHenry, 1986, 1996; Richmond and Jungers, 1995; Stern and Susman, 1983).

The level of sexual dimorphism has further implications for reconstructing social structure. In primates, there is a general finding of associations between monogamous species and low sexual dimorphism, and between polygynous species and high sexual dimorphism (Alexander et al., 1979; Clutton-Brock and Harvey, 1977; Ford, 1994; Kay et al., 1988; Leutenegger and Cheverud, 1985; Leutenegger and Kelley, 1977; Lindenfors, 2002; Lindenfors and Tullberg, 1998; Mitani et al., 1996; Plavcan, 2000, 2001; Plavcan and Cope, 2001; Plavcan and van Schaik, 1992, 1994, 1997). If this relationship is to be held true for the past, one can draw inferences about the mating system in fossil primates (Andrews, 1983; Fleagle et al., 1980; Greenfield, 1972; Kay, 1982a, b; Kelley, 1986; Kelley and Xu, 1991; Pan et al., 1989; Wu and Oxnard, 1983a, b; Zhang, 1982). The high level of sexual dimorphism in A. afarensis has been a basis for the argument that these early hominids had polygynous social structure, analogous to the one seen in gorillas.

However, there is no consensus about the magnitude of body size dimorphism in this early fossil hominid species. Some have reported a body size dimorphism level as low as that in modern humans, proposing a mating system of monogamy for the early hominids (Reno et al., 2003). Furthermore, there have been disagreements about the pattern of sexual dimorphism: the level of canine dimorphism seems to be low (Leutenegger and Shell, 1987; McHenry, 1992), which may explain the low level of dimorphism in mandibular corpus measurements (Lockwood et al., 1996; Richmond and Jungers, 1995).

There have been several ways to reconcile the seemingly contradictory finding of high body size dimorphism and low canine dimorphism in A. afarensis. One is to argue that canine dimorphism is a better indicator of the level of male-male 
competition than body size dimorphism, since body size can be under selective pressures other than sexual selection, such as predator defense or nutrition (Ford, 1994; Plavcan and van Schaik, 1997). Accordingly, the low canine dimorphism reflects the actual low level of sexual selection in the species. However, considering that canines can also be under selective pressure other than male-male competition (Greenfield and Washburn, 1991), this argument is not compelling.

Another possible explanation is that estimated body sizes, used to generate a measure of sexual dimorphism, are subject to compounding and unpredictable error (Smith, 1996). Body weight dimorphism can be less accurate, either by inaccurate estimation process from skeletal element to body mass, or due to sampling error (Plavcan and van Schaik, 1997). Estimating body size can be particularly challenging in small-bodied hominids such as A. afarensis due to allometry (Ruff, 1987, 1988). Examining the skeletal elements directly without body size estimation would address this issue, which is the approach taken in this paper.

This paper examines two questions: (1) whether sexual dimorphism in a selected sample of skeletal elements of $A$. afarensis is the same as that in living humans, chimpanzees, or gorillas, and (2) whether different skeletal elements reflect variation in sexual dimorphism in the same way. Skeletal elements are examined without converting to body size estimates. This is because different taxa may have different relationships between skeletal elements and body size, so that one method of body size estimation may not be valid for different taxa. Also, different taxa may have different patterns of sexual dimorphism manifested by different elements, which will be overlooked if only body size estimates are examined.

However, directly comparing skeletal measurements instead of body size brings forth two weaknesses: each skeletal element has a much smaller sample size than the sample of body sizes estimated from all elements, and it is the body size that would have the selective advantage, whether it is under sexual selection or natural selection. By focusing on skeletal measurements, important information about behavior might be lost. Yet, the error associated with estimating body size of extinct species can be large, unpredictable, and compounding (Smith, 1996). Although there may be advantages in using estimated body sizes, the methodological costs may be addressed by adopting an alternative approach of directly comparing skeletal elements without the estimation process, as is done in this paper. In this study, the pattern of sexual dimorphism in three skeletal elements of the $A$. afarensis sample is assessed using an alternative method, assigned resampling method (ARM, Lee, 2001). This method approximates the degree of sexual dimorphism without relying on any assumption of sex diagnosis for individual specimens. Estimated sexual dimorphism in the A. afarensis sample is compared to three closely related species, modern humans, chimpanzees, and gorillas.

\section{Materials}

Hadar of the Afar triangle region of Ethiopia has yielded the largest sample of A. afarensis, thought to represent from 40 to 100 individuals (Wolpoff, 1999). 
Hominid fossils were discovered from a stratigraphic sequence formed within a relatively narrow span of time, radiometrically dated between 3.40 and $2.95 \mathrm{Ma}$ (Walter, 1994). Its relatively large sample size allows statistical analyses and the narrow span of time from one site indicates that temporal and geographical variation might not play a large role.

Materials used in this study are measurements of metric variables of the mandibular canine, humerus, and femur that have enough representation in the Hadar sample for statistical validity. Data were kindly provided by Milford Wolpoff, who took measurements on original fossils. Table 1 lists the specimens used in this study.

Mandibular canine: Four Hadar specimens have mesio-distal length (AL 128-23 (right), AL 333-103, AL 333w-58, AL 400-1) and six (AL 128-23 (right), AL 333-103, AL 333w-10, AL 333w-58, AL 333w-60, AL 400-1) have bucco-lingual breadth measurements that were analyzed in this study. Although strong arguments have been made that canine height provides a better measure of the level of sexual selection (Plavcan, 2002; Plavcan and van Schaik, 1992, 1997), cross-sectional measurements were used because there are almost no unworn canines in the Hadar sample.

Femur: Two variables have measurements from the largest number of fossil specimens, on the femoral shaft below the lesser trochanter: antero-posterior diameter and medio-lateral diameter. Seven specimens from the Hadar sample made up the fossil data which had measurements for the two shaft diameter variables: AL 128-1 (left), AL 129-1 (right), AL 211-1 (right), AL 288-1 (left), AL 333-3 (right), AL 333-95 (right), and AL 333w-40 (left).

Humerus: There are no variables on the humerus that provide a sufficient sample of Hadar specimens. Two variables for the humerus, breadth of the articular surface of the anterior face and biepicondylar breadth, are measured in three Hadar specimens: AL 137-48a (right), AL 288-1 (left), and AL 322-1 (left). Considering the importance of the humerus, both as a major long bone, reflecting overall body size and the issue of possible differences in dimorphism in different skeletal elements, this study performs the same analysis on the two observed values of Afar specimens, but with an understanding that the results may be of limited validity due to small sample size.

Table 1. Fossil sample used in this study

\begin{tabular}{lll}
\hline Femur & Mandibular canine & Humerus \\
\hline AL 128-1 & AL 128-23 & AL 137-48a \\
AL 129-1 & AL 333-103 & AL 288-1 \\
AL 211-1 & AL 333w-10 & AL 322-1 \\
AL 288-1 & AL 333w-58 & \\
AL 333-3 & AL 333w-60 & \\
AL 333-95 & AL 400-1 & \\
AL 333w-40 & & \\
\hline
\end{tabular}


For the comparative sample, materials from the Cleveland Museum of Natural History were used, with measurements taken by the author. Only adults with an independent record of sex were used, including 40 gorillas ( 20 males, 20 females), 36 chimpanzees (18 males, 18 females), and 40 humans (20 males, 20 females). Measurements were taken on the left side as there were more complete specimens available than on the right side. When the left side was absent, measurements were taken on the right side if there were no signs of asymmetry in other skeletal elements.

\section{Methods}

Documenting the magnitude and pattern of sexual dimorphism in early hominids is important in understanding morphological variation and will possibly illuminate the social structure of ancestral humans. However, estimating sexual dimorphism in extinct hominids is not a straightforward task. A critical challenge is the fact that sex cannot be ascertained in most extinct hominid fossil specimens. Since male and female averages are often used in measures of sexual dimorphism, uncertainty of sex in individual data points is an obstacle in assessing the magnitude of sexual dimorphism.

Several methods have been proposed to estimate the degree of sexual dimorphism in samples of unknown sex, from relatively simple methods using range, mean/ median, or coefficient of variation (Arsuaga et al., 1997; Fleagle et al., 1980; Johanson and White, 1979; Jungers, 1988a; Kay, 1982a; Kimbel and White, 1988; Leutenegger and Shell, 1987; Lockwood et al., 1996; McHenry, 1986, 1991; Plavcan and van Schaik, 1994; Richmond and Jungers, 1995; Wood, 1976; Zihlman, 1985), to more complex methods (Bennett, 1981; Josephson et al., 1996). These methods have been shown to have various levels of precision and accuracy, with simple methods performing as well as, if not better than, more complex methods (Cope and Lacy, 1995; Godfrey et al., 1993; Plavcan, 1994). However, they still need to solve the problem that conventional measures of sexual dimorphism do not provide, that is confidence intervals that allow comparison of different samples.

The ARM (Assigned Resampling Method) is designed to estimate sexual dimorphism in samples of unknown sex (Lee, 2001), which is often the case for hominid fossil samples. ARM gives an estimate of sexual dimorphism with variance. Its algorithm starts with drawing a pair of values with replacement, and calculating a ratio by dividing the larger by the smaller of the pair. A filter that excludes the pairs that have both values drawn from either end of the range of values of the mixed-sex distribution is incorporated to reduce the amount of underestimation. Among filters with different settings, the filter that excludes pairs beyond the range of more than \pm 0.5 standard deviation from the mean was most effective, and hence was incorporated into ARM (Lee, 2001). Distribution of ratios is generated by repeating the sampling 500 times, and the mean of the generated distribution is the ARM estimate of sexual dimorphism. 
ARM was tested using data sets of individuals with known sex. Using 40 metric variables of three species, humans, chimpanzees, and gorillas, ARM estimates were calculated as if sex were not known, then were compared to the observed sexual dimorphism measurement based on known sex for each individual. Since ARM estimates are essentially the mean of ratios, they would diverge from the conventionally used measurement of sexual dimorphism, expressed as the ratio of means. When ARM estimates are plotted against the calculated sexual dimorphism for the test data set, the two variables show positive linear correlation (Fig. 1): ARM estimates track the calculated measurements closely. Furthermore, ARM estimates were robust in samples of arbitrarily biased sex ratios (1:1-4:1) and in small sample size (as small as $n=4$ ), showing acceptable approximation to the observed sexual dimorphism, within $5 \%$ of deviation from the observed values (Lee, 2001).

The deviation between ARM estimates and the calculated numbers increases as the numbers increase, but is not more than $5 \%$. Since the correlation between the two variables is high $\left(R^{2}=0.94\right)$, the regression equation can provide a way to correct for the systematic deviation (Fig. 1, solid line) so that the ARM estimates better approximate the calculated measures of sexual dimorphism. The least-squares regression of the ARM estimates onto the calculated measurements has the regression coefficient of 0.69 and the constant of 0.36 :

$$
y=0.69 x+0.36
$$

where $y$ is the ARM estimate and $x$ is the calculated sexual dimorphism.

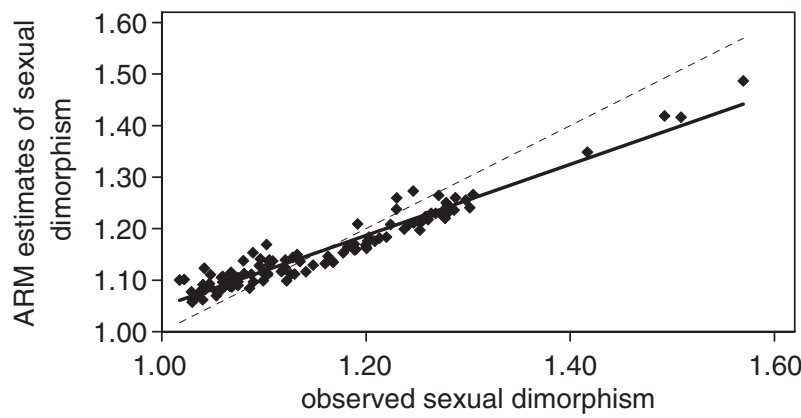

Fig. 1. Scatterplot of ARM estimates and actual sexual dimorphism. Data points are 40 metric variables for humans, chimpanzees, and gorillas, for the total of 120 points. Data points larger than 1.30 are all from gorillas: no metric variable in humans nor in chimpanzees shows a sexual dimorphism so high. $X$-axis is the actual sexual dimorphism of ratio between male and female means, calculated from comparative data of known sex. $Y$-axis is the ARM estimate of sexual dimorphism, generated using the same data, but treating them as if sex were unknown. Solid line shows the least-squares regression: $y=0.69 x+0.36$, where $y=\mathrm{ARM}$ estimates, and $x=$ observed sexual dimorphism. Dotted line shows the isometric relationship $(y=x)$ which would be the case if ARM estimates were exactly the same as the actual measurements. The two variables show positive linear relationship $\left(R^{2}=0.94\right)$. ARM estimate, $y$, is modified so that the corrected ARM estimate, $z=(y-0.36) / 0.69$, has an isometric relation with $x$. See text for details. 
Using the Eq. (1), an ARM estimate, $y$, can be modified so that it converges to an isometric relationship with $x$, its corresponding value of calculated sexual dimorphism. In effect, the solid line in Fig. 1 will be moved to the dotted line. The corrected ARM estimate, $z$, is calculated as follows:

$$
z=(y-0.36) / 0.69
$$

where $y$ is the ARM estimate before correction. With this correction (2), the ARM estimates closely follow the calculated sexual dimorphism, and the two variables form an isometric relationship: $z=x$ (Fig. 1, dotted line). The corrected ARM estimate, $z$, is used in this study (steps (1) through (5) in Appendix A).

Hominid fossil data (discussed in the Materials section) were analyzed using ARM. For each of the variables, sexual dimorphism is estimated from a distribution of resampled ratios, following the procedure outlined above. The corrected ARM estimates for the fossil data were compared against the three comparative species, humans, chimpanzees, and gorillas. By repeating the resampling 500 times, a distribution of ARM estimates was generated for the comparative data (step (6) in Appendix A). The middle $95 \%$ of this distribution, similar to a standard error of the mean, defines the $95 \%$ confidence interval. The null hypothesis of no difference is rejected when an ARM estimate of the fossil sample is beyond the $95 \%$ interval from the comparative data.

\section{Results}

The degree of sexual dimorphism in mandibular canines for the Hadar sample is similar to chimpanzees, significantly lower than gorillas, and significantly higher than humans (Figs. 2(a) and (b)). For canine mesio-distal length $(n=4)$, the ARM value for the Hadar sample is 1.249 , which is significantly lower than gorilla $(95 \%$ confidence interval 1.428-1.473). It is significantly higher than chimpanzee $(95 \%$ confidence interval 1.199-1.235), although within the range of chimpanzee
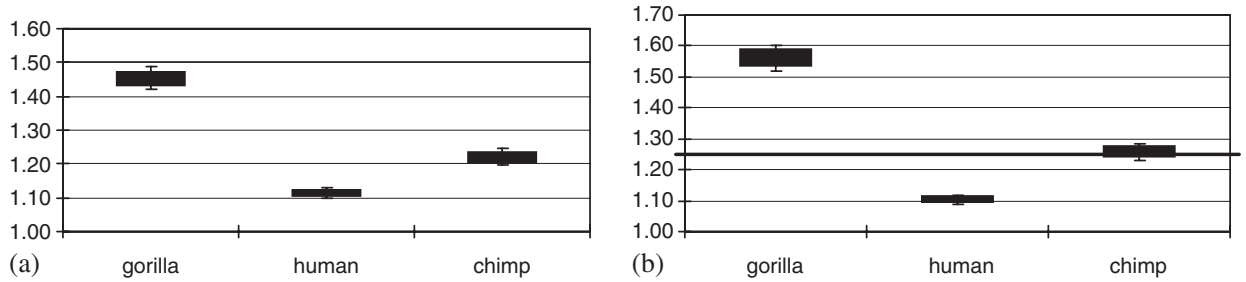

Fig. 2. Comparison of ARM sexual dimorphism in mandibular canine measurements: (a) mesio-distal length and (b) bucco-lingual breadth. $Y$-axis is the ARM estimate of sexual dimorphism. Solid box indicates the $95 \%$ confidence interval for the ARM estimate, with the range defined by maximum and minimum values marked by vertical lines. The ARM estimate for the Afar sample is expressed in solid line. 
(1.195-1.254), and higher than humans (95\% confidence interval 1.104-1.125). For canine bucco-lingual breadth $(n=6)$, the ARM value for Hadar sample is 1.254 , which is significantly lower than gorilla (95\% confidence interval 1.532-1.592), and significantly higher than humans (95\% confidence interval 1.094-1.116). However, the Hadar sample ARM value is not different from chimpanzee $(95 \%$ confidence interval 1.237-1.279). Not surprisingly, humans show significantly lower sexual dimorphism than chimpanzees.

For femoral variables $(n=7)$, the degree of sexual dimorphism in the Hadar sample is similar to or significantly higher than gorillas (Figs. 3(a) and (b)). For the antero-posterior shaft diameter of the femur below the lesser trochanter, the ARM value for Hadar sample is 1.420 , which is significantly higher than gorilla $(95 \%$ confidence interval $1.242-1.272$, range $1.233-1.282)$, humans (95\% confidence interval 1.126-1.150, range $1.122-1.155)$, or chimpanzees $(95 \%$ confidence interval 1.049-1.064, range 1.045-1.068). For the medio-lateral shaft diameter of femur below the lesser trochanter, the ARM value for the Hadar sample is 1.293, which is not different from gorillas (95\% confidence interval 1.270-1.300), but is significantly
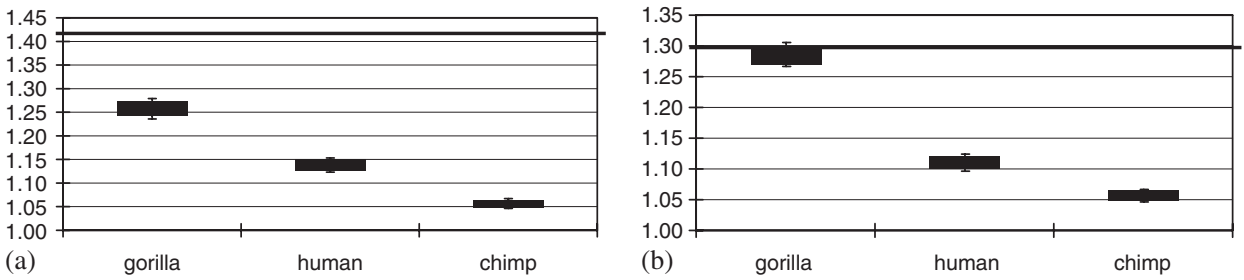

Fig. 3. Comparison of ARM sexual dimorphism in two femur variables: (a) Antero-posterior diameter below lesser trochanter of femur, (b) medio-lateral diameter below lesser trochanter of femur. $Y$-axis is the ARM estimate of sexual dimorphism. Solid box indicates the $95 \%$ confidence interval for the ARM estimate, with the range defined by maximum and minimum values marked by vertical lines. The ARM estimate for the Afar sample is expressed in solid line.
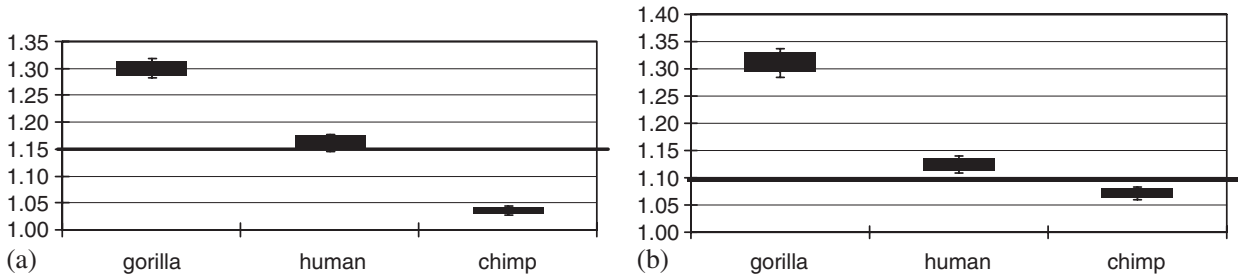

Fig. 4. Comparison of ARM sexual dimorphism in two humerus variables: (a) Breadth of the articular surface, (b) biepicondylar breadth. $Y$-axis is the ARM estimate of sexual dimorphism. Solid box indicates the 95\% confidence interval for the ARM estimate, with the range defined by maximum and minimum values marked by vertical lines. The ARM estimate for the Afar sample is expressed in solid line. 
higher than humans $(95 \%$ confidence interval 1.101-1.120, range 1.094-1.125), or chimpanzees (95\% confidence interval 1.049-1.065, range 1.045-1.068).

For humeral variables $(n=3)$, the degree of sexual dimorphism in the Hadar sample is similar to modern humans (Figs. 4(a) and 4(b)). The ARM values for the Hadar sample are low for both the articular surface of the anterior face (lower than the $95 \%$ interval of modern humans, but within the range) and the biepicondylar breadth (lower than the modern human range). However, as the sample size of Hadar humeral sample is too small, the results need to be interpreted with caution.

\section{Discussion and conclusion}

This study reports that an $A$. afarensis sample shows high sexual dimorphism in femoral shaft variables. To the extent that femoral shaft diameter reflects body size, such a finding supports previous studies that argue for a high level of body size sexual dimorphism in A. afarensis (Cole and Smith, 1987; Frayer and Wolpoff, 1985; Johanson and White, 1979; Johanson et al., 1978; Jungers, 1988b; Kimbel and White, 1988; Leutenegger and Shell, 1987; Lockwood et al., 1996; McHenry, 1986, 1996; Richmond and Jungers, 1995; Stern and Susman, 1983). Considering that hominids show a strong positive allometry in the relationship between hindlimb articular surface and body mass (Ruff, 1988), the estimated high level of sexual dimorphism in a small-bodied hominid should be interpreted accordingly.

Body size may explain the variation in sexual dimorphism in many species of insects, birds, and mammals (Frayer and Wolpoff, 1985, and references therein). Large primates tend to express sexual dimorphism in the form of body weight dimorphism (Gaulin and Sailer, 1984). For a species that is already large, the cost of an increase in size is lower, and larger size has increased benefits in intrasexual competition. It is argued that the degree of sexual dimorphism is expected to increase both relatively and absolutely with an increase in body size, and hence it is an argument for allometry (Leutenegger and Cheverud, 1982, 1985; Leutenegger and Larson, 1985). However, allometry does not seem to be the sole causal factor of sexual dimorphism in primates. A stark contrast can be observed in two studies, where one claims that body size explains $83 \%$ of the variance in sexual dimorphism (Leutenegger, 1982b), while in the other study less than $20 \%$ of the variance is attributable to body size (Gaulin and Sailer, 1984). As this study compares the skeletal elements directly, effects of allometry would be less than is the case with estimated body sizes.

The low level of canine dimorphism should be interpreted with caution in light of studies showing that occlusal dimensions of the canine crown (mesio-distal and bucco-lingual measurements) are less informative than canine height measurements (Plavcan, 2002; Plavcan and van Schaik, 1992, 1997). Plavcan recommends that occlusal measurements be ignored when other measurements of body size dimorphism are available. However, such a recommendation could not be followed in this paper due to the scarcity of canine height data in fossil teeth. 
In the humeral variables, $A$. afarensis shows a degree of sexual dimorphism similar to that of modern humans, consistent with the conclusion that Reno and colleagues reached (Reno et al., 2003), and different from the high level of dimorphism reported in previous studies (Lockwood et al., 1996; Richmond and Jungers, 1995). Considering that these studies, as well as this one, use the same three humeri, the conflicting reports may be due to small sample size. Since a sample size of six is minimally necessary to assume that both sexes are present (Plavcan, 2002), it is quite possible that the humeral data sample contains only one sex; therefore, the result needs to be interpreted with great caution.

Reno and colleagues (Reno et al., 2003) used the relationship between a metric variable and femoral head diameter in one specimen (AL 288-1) to estimate femoral head diameter from various metric variables of other skeletal elements. Their approach has an advantage of pooling fragmentary fossil data and increasing sample size. However, in providing a solution to a problem, their approach may be more problematic in its methodology (Plavcan et al., 2005). Reno and colleagues assume that the relationship between a metric variable and femoral head is the same for all individuals of a given taxon, regardless of locomotor adaptation. However, it is not so, and different skeletal variables provide different estimated body weights, as is seen in the different results regarding the magnitude of sexual dimorphism in A. afarensis (McHenry, 1986, 1991). The effect of pooling different skeletal elements needs to be examined further. Out of 29 estimated femoral head diameters used in the study by Reno and colleagues (Reno et al., 2003), there are seven humeri, eight femora, two radii, two ulnae, six tibiae, and four fibulae. For comparative purposes, the estimated femoral head diameter data used in the study by Reno and colleagues (Reno et al., 2003, Table 1) were used here (Fig. 5). ARM values for humans are in between those of gorillas and chimpanzees, as expected. All three species show significant difference in their ARM values. However, the Afar sample of 29 data points yielded ARM values higher than that of modern humans and lower than that of gorillas (Fig. 5).

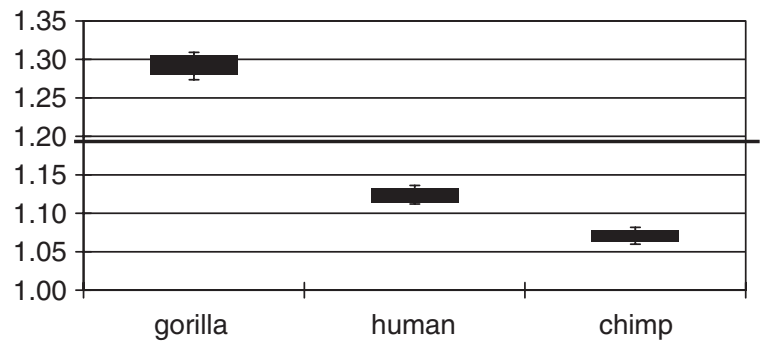

Fig. 5. Comparison of ARM sexual dimorphism in femoral head diameter. $Y$-axis is the ARM estimate of sexual dimorphism. Solid box indicates the $95 \%$ confidence interval for the ARM estimate, with the range defined by maximum and minimum values marked by vertical lines. The ARM estimate for the Afar sample is expressed in solid line. 
The results of this paper suggest that the sexual dimorphism in the Hadar A. afarensis does not follow any of the patterns seen in living African apes or modern humans. The answer to the question whether A. afarensis is highly sexually dimorphic like the gorillas or low like the modern humans, in fact, depends on which skeletal elements are compared. The $A$. afarensis sample examined in this study shows sexual dimorphism like that of gorilla in femoral variables, like that of chimpanzees in mandibular canine variables, and like that of modern humans in humeral variables (notably the results from the humerus data are weaker). Therefore, it can be said that the null hypothesis that different skeletal elements show the same degree of sexual dimorphism is refuted. However, it is also possible that the variation in the magnitude of sexual dimorphism observed in this study is due to sampling error. Since individual skeletal elements have small sample sizes and different individuals were used for each skeletal element, the issue of sampling error needs to be examined in future study.

Although the results of this study are compatible with the conclusions drawn by previous studies that found a high level of body size dimorphism and a low level of canine dimorphism (Lockwood et al., 1996; Richmond and Jungers, 1995), the behavioral implications of such a finding are less clear. Comparative studies have indeed shown sexual selection to be the primary factor to explain variation in sexual dimorphism (Ford, 1994; Plavcan and van Schaik, 1997); however, the relationship is not tight, as there is no clear association between the mating system and sexual dimorphism in primates beyond the fact that high sexual dimorphism is found among polygynous species. For example, polygynous living primates show varying degrees of sexual dimorphism (Milton, 1985; Rowell and Chism, 1986), not only high sexual dimorphism as is predicted. Species characterized by multi-male groups show higher sexual dimorphism than species characterized by single-male groups (PhillipsConroy and Jolly, 1981). This is contrary to what is predicted. For primates, extremely high sexual dimorphism is an indicator of polygyny, but polygyny is not necessarily an indicator of high sexual dimorphism (Ralls, 1977). Relationships with various measures of sexual selection such as socio-economic ratio, harem size, or operational sex ratio, weaken significantly once the monogamous species are excluded (Harvey and Clutton-Brock, 1985; Leutenegger, 1982a, b). Caution is called for when interpreting the level of sexual dimorphism in terms of socio-ecological and behavioral adaptation (Plavcan, 2000, 2002).

\section{Acknowledgements}

I thank Bruce Latimer, Yohannes Haile-Selassie, and Lyman Jellema at the Cleveland Museum of Natural History; and Milford Wolpoff for providing original data. I am grateful to Rachel Caspari, Karen Rosenberg, Francis Thackeray, and two anonymous reviewers for helpful suggestions for improving the paper. The Korean Foundation for Advanced Studies and the University of California at Riverside provided financial support for this study. 


\section{Appendix A. Algorithm of ARM}

The algorithm of ARM consists of the following steps:

(1) Two values, $x_{a}$ and $x_{b}$, are randomly sampled with replacement from an empirical data set of size $n\left[x=\left(x_{1}, x_{2}, \ldots, x_{n}\right)\right]$.

(2) If both values of $x_{a}$ and $x_{b}$ are from the range of values more than mean +0.5 standard deviation, or if they are from the range of values less than mean -0.5 standard deviation, the pair is considered invalid.

(3) If not (2), $x_{a}$ and $x_{b}$ are compared. If $x_{b}$ is larger than $x_{a}, x_{a}$ and $x_{b}$ form a ratio $r$ by dividing $x_{b}$ by $x_{a}$. Otherwise, $x_{a}$ and $x_{b}$ form a ratio $r$ by dividing $x_{a}$ by $x_{b}$.

(4) Steps (1), (2) and (3) are repeated numerous times until the size of $r$ reaches $m=500$. This results in a distribution of ratios $r_{i}(i=1,2, \ldots, 500)$.

(5) Take the sample mean of the above distribution $(y)$ and apply correction to get the corrected ARM estimate, $z: z=(y-0.36) / 0.69$. This corrected value, $z$, is defined as the ARM estimate of sexual dimorphism.

(6) Steps (1)-(5) are repeated 500 times to yield the standard error of the ARM estimate.

\section{References}

Alexander, R.D., Hoogland, J.L., Howard, R.D., Noonan, K.M., 1979. Sexual dimorphisms and breeding systems in pinnipeds, ungulates, primates, and humans. In: Chagnon, N.A., Irons, W. (Eds.), Evolutionary Biology and Human Social Behavior: An Anthropological Perspective. Duxbury Press, North Scituate, pp. 402-435.

Andrews, P.J., 1983. The natural history of Sivapithecus. In: Ciochon, R.L., Corruccini, R.S. (Eds.), New Interpretations of Ape and Human Ancestry. Plenum, New York, pp. 441-463.

Arsuaga, J.L., Carretero, J.M., Lorenzo, C., Gracia, A., Martínez, I., Bermúdez de Castro, J.M., Carbonell, E., 1997. Size variation in middle pleistocene humans. Science 277, 1086-1088.

Bennett, K.A., 1981. On the expression of sexual dimorphism. Am. J. Phys. Anthropol. 56, 59-62.

Clutton-Brock, T.H., Harvey, P.H., 1977. Sexual dimorphism, socioeconomic sex ratio, and body weight in primates. Nature 269, 797-800.

Cole III, T.M., Smith, F.H., 1987. An odontometric assessment of variability in Australopithecus afarensis. Hum. Evol. 2, 221-234.

Cope, D.A., Lacy, M.G., 1995. Comparative application of the coefficient of variation and range-based statistics for assessing the taxonomic composition of fossil samples. J. Hum. Evol. 29, 549-576.

Fleagle, J.G., Kay, R.F., Simons, E.L., 1980. Sexual dimorphism in early anthropoids. Nature 287, 328-330.

Ford, S.M., 1994. Evolution of sexual dimorphism in body weight in Platyrrhines. Am. J. Primatol. 34, 221-244.

Frayer, D.W., Wolpoff, M.H., 1985. Sexual dimorphism. In: Siegel, B.J., Beals, A.R., Tyler, S.A. (Eds.), Annual Review of Anthropology. Annual Reviews, Palo Alto, pp. 429-473.

Gaulin, S.J.C., Sailer, L.D., 1984. Sexual dimorphism among the primates: the relative impact of allometry and sexual selection. Int. J. Primatol. 5, 515-536.

Godfrey, L.R., Lyon, S.K., Sutherland, M.R., 1993. Sexual dimorphism in large-bodied primates: the case of the subfossil lemurs. Am. J. Phys. Anthropol. 90, 315-334.

Greenfield, L.O., 1972. Sexual dimorphism in Dryopithecus africanus. Primates 13, 395-410.

Greenfield, L.O., Washburn, A., 1991. Polymorphic aspects of male anthropoid canines. Am. J. Phys. Anthropol. 84, 17-34.

Harvey, P.H., Clutton-Brock, T., 1985. Life history variation in primates. Evolution 39, 559-581. 
Johanson, D.C., White, T.D., 1979. A systematic assessment of early African hominids. Science 203, 321-330.

Johanson, D.C., White, T.D., Coppens, Y., 1978. A new species of the genus Australopithecus (Primates: Hominidae) from the Pliocene of eastern Africa. Kirtlandia 28, 1-14.

Josephson, S.C., Juell, K.E., Rogers, A.R., 1996. Estimating sexual dimorphism by method-of-moments. Am. J. Phys. Anthropol. 100, 191-206.

Jungers, W.L., 1988a. Lucy's length: stature reconstruction in Australopithecus afarensis (A.L.288-1) with implications for other small-bodied hominids. Am. J. Phys. Anthropol. 76, 227-231.

Jungers, W.L., 1988b. New estimates of body size in australopithecines. In: Grine, F.E. (Ed.), Evolutionary History of the "Robust" Australopithecines. Aldine de Gruyter, New York, pp. 115-125.

Kay, R.F., 1982a. Sexual dimorphism in Ramapithecinae. Proc. Natl. Acad. Sci. USA 79, $209-212$.

Kay, R.F., 1982b. Sivapithecus simonsi, a new species of Miocene hominoid with comments on the phylogenetic status of the Ramapithecinae. Int. J. Primatol. 3, 113-173.

Kay, R.F., Plavcan, J.M., Glander, K.E., Wright, P.C., 1988. Sexual selection and canine dimorphism in New World monkeys. Am. J. Phys. Anthropol. 77, 385-397.

Kelley, J., 1986. Species recognition and sexual dimorphism in Proconsul and Rangwapithecus. J. Hum. Evol. 15, 461-496.

Kelley, J., Xu, Q., 1991. Extreme sexual dimorphism in a Miocene hominoid. Nature 352, $151-153$.

Kimbel, W.H., White, T.D., 1988. Variation, sexual dimophism, and the taxonomy of Australopithecus. In: Grine, F.E. (Ed.), Evolutionary History of the "Robust" Australopithecines. Aldine de Gruyter, New York, pp. 175-192.

Lee, S.-H., 2001. Assigned resampling method: a new method to estimate size sexual dimorphism in samples of unknown sex. Przegl. Antropol. 64, 21-39.

Leutenegger, W., 1982a. Scaling of sexual dimorphism in body weight and canine size in primates. Folia Primatol. 37, 163-176.

Leutenegger, W., 1982b. Sexual dimorphism in nonhuman primates. In: Hall, R.L. (Ed.), Sexual Dimorphism in Homo sapiens: a Question of Size. Praeger, New York, pp. 11-36.

Leutenegger, W., Cheverud, J.M., 1982. Correlates of sexual dimorphism in primates. Int. J. Primatol. 3, $387-402$.

Leutenegger, W., Cheverud, J.M., 1985. Sexual dimorphism in primates. The effects of size. In: Jungers, W.L. (Ed.), Size and Scaling in Primate Biology. Plenum, New York, pp. 33-50.

Leutenegger, W., Kelley, J.T., 1977. Relationships of sexual dimorphism in canine size and body size to social, behavioural, and ecological correlates in anthropoid primates. Primates 18, 177-186.

Leutenegger, W., Larson, S., 1985. Sexual dimorphism in the postcranial skeleton of New World primates. Folia Primatol. 44, 82-95.

Leutenegger, W., Shell, B., 1987. Variability and sexual dimorphism in canine size of Australopithecus and extant hominoids. J. Hum. Evol. 16, 359-367.

Lindenfors, P., 2002. Sexually antagonistic selection on primate size. J. Evol. Biol. 15, 595-607.

Lindenfors, P., Tullberg, B.S., 1998. Phylogenetic analyses of primate size evolution: the consequences of sexual selection. Biol. J. Linn. Soc. Lond. 64, 413-447.

Lockwood, C.A., Richmond, B.G., Jungers, W.L., Kimbel, W.H., 1996. Randomization procedures and sexual dimorphism in Australopithecus afarensis. J. Hum. Evol. 31, 537-548.

McHenry, H.M., 1986. Size variation in the postcranium of Australopithecus afarensis and extant species of hominoidea. In: Pickford, M.H.L., Chiarelli, B. (Eds.), Sexual Dimorphism in Living and Fossil Primates. Il Sedicesimo, Firenze, pp. 183-189.

McHenry, H.M., 1991. Sexual dimorphism in Australopithecus afarensis. J. Hum. Evol. 20, $21-32$.

McHenry, H.M., 1992. Body size and proportions in early hominids. Am. J. Phys. Anthropol. 87, $407-431$.

McHenry, H.M., 1996. Sexual dimorphism in fossil hominids and its socioecological implications. In: Steele, J., Shennan, S. (Eds.), The Archaeology of Human Ancestry. Routledge, New York, pp. 91-109.

Milton, K., 1985. Mating and absence of canine tooth dimorphism in woolly spider monkeys Brachyteles arachnoides. Am. J. Phys. Anthropol. 68, 519-523.

Mitani, J.C., Gros-Louis, J., Richards, A.F., 1996. Sexual dimorphism, the operational sex ratio, and the intensity of male competition in polygynous primates. Am. Nat. 147, 966-980.

Olson, T.R., 1985. Cranial morphology and systematics of the Hadar Formation hominids and "Australopithecus" africanus. In: Delson, E. (Ed.), Ancestors: The Hard Evidence. Alan Liss, New York, pp. 102-119. 
Pan, Y., Waddle, D.M., Fleagle, J.G., 1989. Sexual dimorphism in Laccopithecus robustus, a late Miocene hominoid from China. Am. J. Phys. Anthropol. 79, 137-158.

Phillips-Conroy, J.E., Jolly, C.J., 1981. Sexual dimorphism in two subspecies of Ethiopean baboons (Papio hamadryas) and their hybrids. Am. J. Phys. Anthropol. 56, 115-130.

Plavcan, J.M., 1994. Comparison of four simple methods for estimating sexual dimorphism in fossils. Am. J. Phys. Anthropol. 94, 465-476.

Plavcan, J.M., 2000. Inferring social behavior from sexual dimorphism in the fossil record. J. Hum. Evol. $39,327-344$.

Plavcan, J.M., 2001. Sexual dimorphism in primate evolution. Yearb. Phys. Anthropol. 44, 25-53.

Plavcan, J.M., 2002. Reconstructing social behavior from dimorphism in the fossil record. In: Plavcan, J.M., Kay, R.F., Jungers, W.L., van Schaik, C.P. (Eds.), Reconstructing Behavior in the Primate Fossil Record. Kluwer Academic/Plenum Publishers, New York, pp. 297-338.

Plavcan, J.M., Cope, D.A., 2001. Metric variation and species recognition in the fossil record. Evol. Anthropol. 10, 204-222.

Plavcan, J.M., van Schaik, C.P., 1992. Intrasexual competition and canine dimorphism in anthropoid primates. Am. J. Phys. Anthropol. 87, 461-477.

Plavcan, J.M., van Schaik, C.P., 1994. Canine dimorphism. Evol. Anthropol. 6, 208-214.

Plavcan, J.M., van Schaik, C.P., 1997. Interpreting hominid behavior on the basis of sexual dimorphism. J. Hum. Evol. 32, 345-374.

Plavcan, J.M., Kay, R.F., Jungers, W.L., van Schaik, C.P., 2002. Reconstructing Behavior in the Primate Fossil Record. Kluwer Academic/Plenum Publishers, New York.

Plavcan, J.M., Lockwood, C.A., Kimbel, W.H., Lague, M.R., Harmon, E.H., 2005. Sexual dimorphism in Australopithecus afarensis revisited: how strong is the case for a human-like pattern of dimorphism? J. Hum. Evol. 48, 313-320.

Ralls, K., 1977. Sexual dimorphism in mammals: avian models and unanswered questions. Am. Nat. 11, 917-938.

Reno, P.L., Meindl, R.S., McCollum, M.A., Lovejoy, C.O., 2003. Sexual dimorphism in Australopithecus afarensis was similar to that of modern humans. Proc. Natl. Acad. Sci. USA 100, 9404-9409.

Richmond, B.G., Jungers, W.L., 1995. Size variation and sexual dimorphism in Australopithecus afarensis and living hominoids. J. Hum. Evol. 29, 229-245.

Rowell, T.E., Chism, J., 1986. Sexual dimorphism and mating systems: jumping to conclusions. Hum. Evol. 1, 215-219.

Ruff, C.B., 1987. Structural allometry of the femur and tibia in Hominoidea and Macaca. Folia Primatol. 48, 9-49.

Ruff, C.B., 1988. Hindlimb articular surface allometry in Hominoidea and Macaca, with comparisons to diaphyseal scaling. J. Hum. Evol. 17, 687-714.

Smith, R.J., 1996. Biology and body size in human evolution. Curr. Anthropol. 37, 451-481.

Stern Jr., J.T., Susman, R.L., 1983. The locomotor anatomy of Australopithecus afarensis. Am. J. Phys. Anthropol. 60, 279-317.

Walter, R.C., 1994. Age of Lucy and the first family: single-crystal 40Ar/39Ar dating of the Denen Dora and lower Kada Hadar members of the Hadar Formation, Ethiopia. Geology 22, 6-10.

Wolpoff, M.H., 1999. Paleoanthropology, second ed. McGraw-Hill, New York.

Wood, B.A., 1976. The nature and basis of sexual dimorphism in the primate skeleton. J. Zool. (Lond.) $180,15-34$.

Wu, R., Oxnard, C.E., 1983a. Ramapithecines from China: evidence from tooth dimensions. Nature 306 , $258-259$.

Wu, R., Oxnard, C.E., 1983b. Ramapithecus and Sivapithecus from China: some implications for higher primate evolution. Am. J. Primatol. 5, 303-344.

Zhang, Y., 1982. Variability and evolutionary trends in tooth size of Gigantopithecus blacki. Am. J. Phys. Anthropol. 59, 21-32.

Zihlman, A.L., 1985. Australopithecus afarensis: two sexes or two species? In: Tobias, P.V. (Ed.), Hominid Evolution: Past, Present, and Future. Proceedings of the Taung Diamond Jubilee International Symposium. Alan R. Liss, New York, pp. 213-220. 